(1)

CrossMark

\title{
Examining the intubation decision in randomised clinical trials
}

\author{
To the Editor:
}

ToBin et al. [1] pointed in their editorial to the limitations of randomised trials in determining the effect of noninvasive modalities on the intubation of patients with respiratory failure. My colleagues and I have recently examined many design aspects of 53 randomised trials that evaluated the effect of noninvasive ventilation and high flow oxygen therapy on the outcomes of patients with acute respiratory failure [2]. Our findings support many of the points highlighted in the editorial.

First, trial circumstances vary significantly. Patients were enrolled into the reviewed trials if they met a definition of respiratory failure that, on average, included four criteria. The most commonly used criterion was respiratory rate, with $79 \%$ of the trials requiring a patient to have a rate above a certain threshold. However, the range of the threshold was wide (from 20 breaths per min to 36 breaths per min). The range for the arterial-to-inspired oxygen $\left(P_{\mathrm{aO}_{2}} / F_{\mathrm{IO}_{2}}\right)$ ratio, which was a criterion in $50 \%$ of trials, was also wide (from 170 to 400). Although the averages of these two variables indicated that patients were generally tachypnoeic (mean rate 31 breaths per min) and hypoxaemic (ratio 174), the coefficients of variation for these variables were large (23\% and $38 \%$, respectively) [2]. It seems difficult to believe that experienced clinicians would consider all of these patients as candidates for respiratory support beyond a simple facemask.

Second, breathing effort, the most common reason for intubation [3], was neglected in clinical trials. We found that breathing effort and dyspnoea were less frequently included in the definition of respiratory failure (39\% and $28 \%$, respectively) than respiratory rate and the ratio. They were also rarely reported $(0 \%$ and $7 \%$, respectively). The same was true for using breathing effort as a criterion for intubation. We also found that the language used to describe breathing effort was vague and extremely variable [2].

Third, clinicians do not intubate based on a criteria, but clinical trials frequently have them. In our review, we found that intubation decision was based on eight criteria. These criteria were combined in various ways: $53 \%$ of trials required fulfilling any of the criteria, $30 \%$ required fulfilling more than one, and $17 \%$ did not indicate how to use the criteria. Two thirds of the trials did not provide a clinical justification or a reference for the intubation criteria [2]. We also identified that none of the trials reported how patients were monitored to ascertain when they met the intubation criteria. Were the patients examined at set intervals to determine when they met enough criteria for intubation? Or were the clinicians and investigators triggered by their gestalt that a patient's condition deteriorated and then decided to determine if the intubation criteria were met?

Fourth, the individuals making the intubation decisions vary. Although investigators and clinicians are surely concerned about patient outcomes, the investigators are also interested in confirming their hypothesis, while clinicians want to avoid unnecessary interventions. We found that in $45 \%$ of the trials the patient's primary team made the intubation decision and that $47 \%$ of the trials did not specify who made the decision [2].

To highlight the disagreement between intubation criteria and the clinical decision for intubation, we identified seven trials that reported the percentage of patients that met the intubation criteria and the percentage of patients that were intubated. On average, $40 \%$ of the patients that met intubation criteria were intubated [2]. In other words, if the intubation decisions were based solely on the criteria, $60 \%$ of the intubation would have been unwarranted, unethical, and harmful.

@ERSpublications

Criteria used in clinical trials to identify patients with respiratory failure and for when to intubate them might not be applicable to clinical practice https://bit.ly/3qAmCYt

Cite this article as: Tulaimat A. Examining the intubation decision in randomised clinical trials. Eur Respir J 2021; 57: 2100051 [https://doi.org/10.1183/13993003.00051-2021]. 
Aiman Tulaimat (1)

The Division of Pulmonary, Critical Care and Sleep Medicine, Cook County Health, Chicago, IL, USA.

Correspondence: Aiman Tulaimat, The Division of Pulmonary, Critical Care and Sleep Medicine, Cook County Health, 1950 West Polk Street, Room 8205, Chicago, IL, USA. E-mail: atulaimat@cookcountyhhs.org

Received: 7 Jan 2021 | Accepted: 12 Jan 2021

Conflict of interest: A. Tulaimat has nothing to disclose.

\section{References}

1 Tobin MJ, Jubran A, Laghi F. Noninvasive strategies in COVID-19: epistemology, randomised trials, guidelines, physiology. Eur Respir J 2021; 57: 2004247.

2 Hakim R, Watanabe-Tejada L, Sukhal S, et al. Acute respiratory failure in randomized trials of noninvasive respiratory support: a systematic review of definitions, patient characteristics, and criteria for intubation. J Crit Care 2020; 57: 141-147.

3 Tobin MJ, Jubran A, Laghi F. Hypoxaemia does not necessitate tracheal intubation in COVID-19 patients. Comment on Br J Anaesth 2021; 126: 44-7. Br J Anaesth 2021: 126: e75-e76.

Copyright @The authors 2021. This version is distributed under the terms of the Creative Commons Attribution Non-Commercial Licence 4.0. For commercia reproduction rights and permissions contact permissionsdersnet.org 